\title{
Food Access and Experience of Food Insecurity in Nigerian Households during the COVID-19 Lockdown
}

\section{Folake O. Samuel ${ }^{1}$, Toluwalope E. Eyinla ${ }^{1 *}$, Ariyo Oluwaseun${ }^{1}$, Oluwatosin 0. Leshi' ${ }^{1}$, Bartholomew I. C. Brai², Wasiu A. O. Afolabi ${ }^{3}$}

${ }^{1}$ Department of Human Nutrition and Dietetics, University of Ibadan, Ibadan, Nigeria

${ }^{2}$ Department of Biochemistry, Federal University, Oye-Ekiti, Nigeria

${ }^{3}$ Department of Nutrition and Dietetics, Federal University of Agriculture, Abeokuta, Nigeria

Email: ^toluemma@ymail.com

How to cite this paper: Samuel, F.O., Eyinla, T.E., Oluwaseun, A., Leshi, O.O., Brai, B.I.C. and Afolabi, W.A.O. (2021) Food Access and Experience of Food Insecurity in Nigerian Households during the COVID-19 Lockdown. Food and Nutrition Sciences, 12, 1062-1072.

https://doi.org/10.4236/fns.2021.1211078

Received: October 14, 2021

Accepted: November 15, 2021

Published: November 18, 2021

Copyright $\odot 2021$ by author(s) and Scientific Research Publishing Inc. This work is licensed under the Creative Commons Attribution International License (CC BY 4.0).

http://creativecommons.org/licenses/by/4.0/

\begin{abstract}
The food insecurity experiences and related behaviors of Nigerian households during the COVID-19 lockdown have not been fully discussed. This study was conducted to elicit information on the impact of COVID-19 lockdown on economic and behavioral patterns related to food access. An online-based semi-structured questionnaire distributed through messaging platforms was used to collect information on characteristics, food purchasing behaviour before and during COVID-19 lockdown among respondents. Experience of food insecurity was assessed using Food Insecurity Experience Scale (FIES). A total of 883 responses were received and analyzed using SPSS Version 20.0. Most of the respondents $(90.5 \%)$ were at home or had stopped going to work due to COVID-19 restrictions. Even though smaller households had higher food expenditure claims than larger households $(p=0.012)$, the larger the household, the more acute the challenge of economic access to food $(p=0.050)$. Location $(p=0.000)$, age $(p=0.003)$, occupation $(p=0.014)$ and income level $(p=0.000)$ were associated with experience of food insecurity. In conclusion, lockdown restrictions increased food expenditure and experience of food insecurity among the respondents and thus we recommend the probe of longterm consequences of deviations from usual food access on undernutrition or overnutrition in Nigerian households.
\end{abstract}

\section{Keywords}

Food Security, COVID-19, FIES, Lockdown, Food Access 


\section{Introduction}

The Nigerian index case of the novel coronavirus was announced in February 2020. By March 29th 2020, the federal government of Nigeria declared nationwide lockdown which included bans on inter-state traveling, non-essential economic and related activities. Though the lockdown restrictions were helpful in curtailing the spread of COVID-19, consequences on the nation's fragile food system and livelihoods of households were soon evident. Such consequences were not unexpected following high burden of poverty in Nigeria. In addition, predictions of food access hardship were becoming evident as the lockdown progressed (and even beyond) which further placed a burden on not-too robust food systems [1] [2]. Prior to COVID-19 pandemic, food insecurity was high in Nigeria with prevalence range of $30 \%-81 \%$ [1] [2] [3] [4]. This could be attributed to the fragile food system in the country occasioned by high dependence on rain-fed, subsistence agriculture often accompanied by poor yield and limited value addition along the various agricultural value chains. Food insecurity is a barrier to healthy eating habits, which is important to reduce susceptibility to and longterm complications from COVID-19 [5] [6]. With the lockdown, restriction of movements and other measures to curtail the spread of coronavirus, the fragile food system was further strained leading to restricted distribution of food and a sharp rise in the price of food commodities. This peculiar situation thus justifies the need to provide research evidence of the impact of COVID-19 lockdown on food access. This study was therefore conducted to elicit information on the economic and behavioral patterns related to food access and food security in Nigeria especially during the COVID-19 lockdown.

\section{Methodology}

\subsection{Study Design and Data Collection}

This study was descriptive and cross-sectional in design. An online-based questionnaire was shared through messaging platforms to elicit information on socio-demographic and socioeconomic characteristics, food expenditure and purchasing behavior during Nigeria's nationwide lockdown months of April and May, 2020. Respondents' participation was entirely voluntary and anonymous.

\subsection{Data Management and Analysis}

Responses were received in a spreadsheet and transferred into Statistical Package for Social Sciences (SPSS) version 20.0. A total of 883 responses were received before data cleaning commenced. Data processing of the FIES questions was carried out using the methodology presented by the Food and Agriculture Organization [7] [8]. The discrete assignment approach was used to further classify responses from the FIES module. The cleaned data were analyzed and presented using descriptive and inferential statistics. Chi-square was used to test for statistical associations between variables. Significance was set at $\mathrm{p}<0.05$. 


\section{Results and Discussion}

\subsection{Characteristics of Respondents}

A summary of responses showed that most of the respondents (90.5\%) were staying at home or had stopped going to work due to COVID-19 lockdown restrictions. The socio-demographic, economic and household characteristics of respondents are presented in Table 1. Responses were mostly from urban residents $(62.0 \%)$ and only $8.3 \%$ in rural areas. The age categories of respondents revealed that $37.1 \%$ were aged 21 - 30 years, $30.4 \%$ were $31-40$ years, and $18.2 \%$ were 41 - 50 years. Households with 4 - 6 members were predominant (55.3\%) and those with more than 10 members constituted only $4.2 \%$. Household composition showed that about $25 \%$ of all respondents had at least one household member who was aged below 5, 5 - 9 and $10-17$ years of age. Most of the respondents had at least a post-secondary education (97.1\%). Occupational distribution showed that $27.5 \%$ were in professional/managerial cadre and $15.3 \%$ were into sales and services while $16.0 \%$ were unemployed. The income pattern of respondents showed that $66.7 \%$ earned monthly salary and $7.2 \%$ earned daily income. Over half of the respondents $(63.1 \%)$ had experienced lack of money in the previous 4 weeks prior to the survey. A similar impact of restrictions on source of livelihood and income has been reported in Ethiopian households [9] and this appears to be a worldwide pattern resulting from lockdown restrictions seeking to control the spread of COVID-19.

Table 1. Sociodemographic and socioeconomic characteristics of respondents.

\begin{tabular}{cc}
\hline \multicolumn{1}{c}{ Characteristics of Respondents } \\
\hline \multicolumn{1}{c}{ Characteristics } & Frequency (\%) \\
\hline Categorization of neighborhood $(\mathbf{n}=\mathbf{8 6 5})$ & $72(8.3)$ \\
\hline Rural & $257(29.7)$ \\
Semi-Urban & $536(62.0)$ \\
Urban & \\
\hline Age Category $(\mathbf{n}=\mathbf{8 6 3})$ & $82(0.9)$ \\
\hline$<20$ years & $320(37.1)$ \\
$21-30$ years & $262(30.4)$ \\
$31-40$ years & $157(18.2)$ \\
$41-50$ years & $90(10.4)$ \\
$51-60$ years & $26(3.0)$ \\
$>60$ years & \\
\hline Household Size $(\mathrm{n}=\mathbf{8 5 2})$ & $222(26.1)$ \\
\hline$<3$ members & $471(55.3)$ \\
$4-6$ members & $123(14.4)$ \\
7 - 9 members & $36(4.2)$ \\
\hline 10 members &
\end{tabular}




\section{Continued}

\begin{tabular}{|c|c|}
\hline \multicolumn{2}{|c|}{ Household Demographic Distribution (Yes responses) } \\
\hline Below 5 years & $228(100.0)$ \\
\hline $5-9$ years & $201(100.0)$ \\
\hline $10-17$ years & $286(100.0)$ \\
\hline 18 years and above & $726(100.0)$ \\
\hline \multicolumn{2}{|l|}{ Main Occupation $(\mathrm{n}=825)$} \\
\hline Professional/technical/managerial & $227(27.5)$ \\
\hline Clerical & $88(10.7)$ \\
\hline Sales and services & $126(15.3)$ \\
\hline Skilled manual & $207(25.1)$ \\
\hline Unskilled manual & $38(4.6)$ \\
\hline Agriculture & $7(0.8)$ \\
\hline Unemployed & $132(16.0)$ \\
\hline \multicolumn{2}{|l|}{ Usual monthly income in Naira $(n=829)$} \\
\hline$<10,000$ naira & $108(13.0)$ \\
\hline 10,000 - 49,999 naira & $202(24.4)$ \\
\hline 50,000 - 99,999 naira & $144(17.4)$ \\
\hline 100,000 - 149,999 naira & $152(18.3)$ \\
\hline 150,000 - 199,999 naira & $73(8.8)$ \\
\hline$>200,000$ naira & $150(18.1)$ \\
\hline \multicolumn{2}{|l|}{ Usual mode of income $(n=851)$} \\
\hline Irregular income & $202(23.7)$ \\
\hline Daily income & $61(7.2)$ \\
\hline Weekly income & $20(2.4)$ \\
\hline Monthly income (salary) & $568(66.7)$ \\
\hline \multicolumn{2}{|c|}{ In the last 30 days, did you experience lack of money $(n=864)$} \\
\hline Yes & $545(63.1)$ \\
\hline No & $319(36.9)$ \\
\hline
\end{tabular}

\subsection{Impact of Lockdown Situation on Food Purchasing}

The reasons for respondents' current purchasing behavior (ranked in order of popularity of response) are also presented (Table 2). Respondents who now purchased less than their usual food stock gave "insufficient money for food" as their main reason. For respondents who now purchased more than usual, the most popular response was "because everyone is home we now eat more as there's nowhere to go" and the least popular was "because I am at home, I now eat all my meals at home instead of eating out". Those whose purchasing behavior did not change mostly said "my income and budget have not changed". 
Table 2. Reasons for current purchasing behavior.

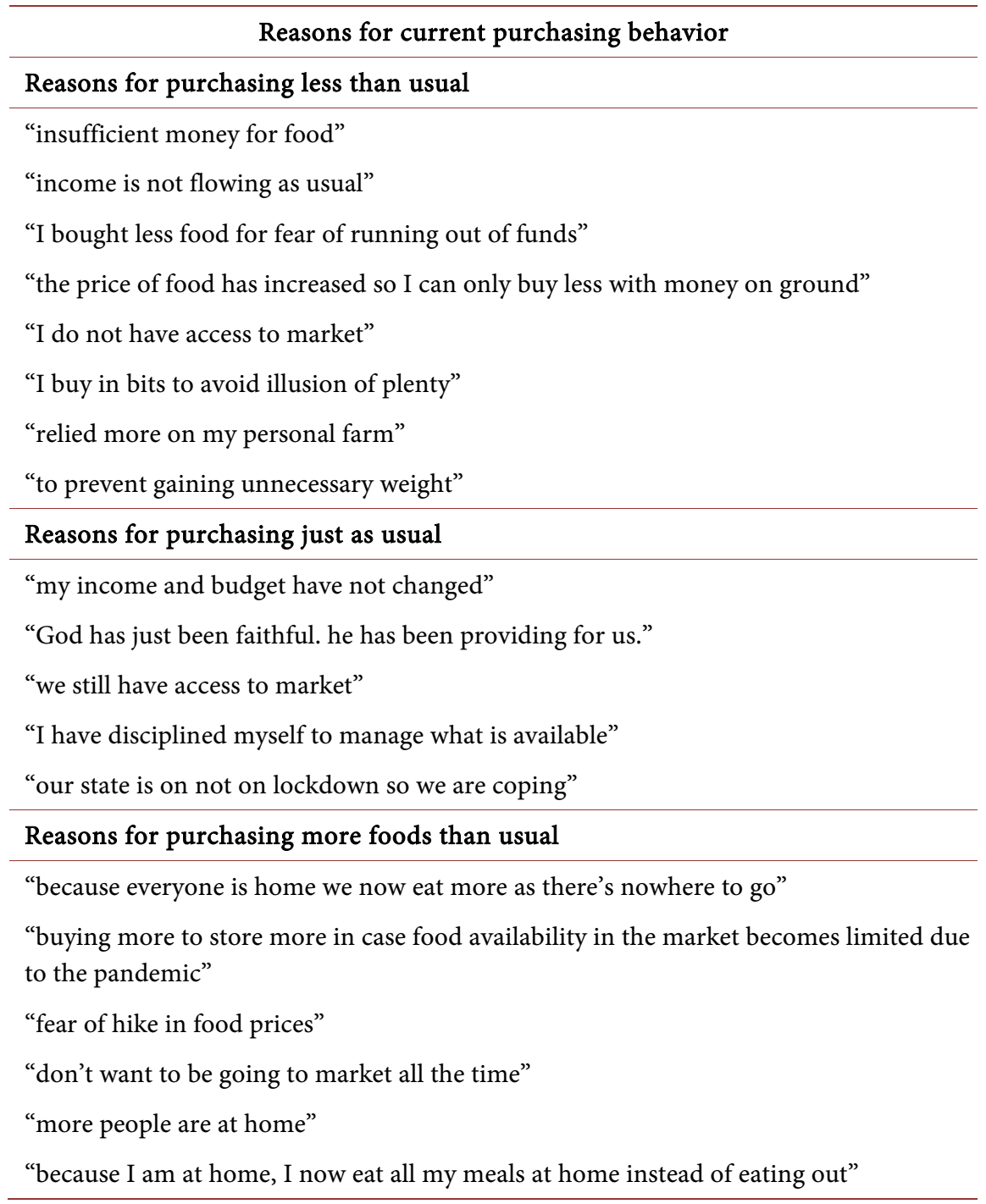

Generally, restrictions resulted in alterations to food purchasing. While the decision to buy less was influenced more by purchasing power of the individual/household, those who bought more, mainly did so out of necessity and uncertainty. Most respondents claimed to deviate from their usual purchasing pattern (Table 3). More households purchased extra food than usual during the lockdown and accounted to 386 (43.7\%) of all respondents compared to those who purchased less (31.8\%). Baker et al., 2020 [10] examined the purchasing pattern of American households and found substantial alteration in food expenditure which initially increased as lockdown restrictions were introduced. In this study, majority (63.3\%) expressed worry that lockdown extension could affect ability to feed and $48.2 \%$ had experienced insufficient money for food expenditure or inadequate food supply in the period of 7 days preceding the survey. Disaggregation of food purchase activities by household size revealed that households with $<3$ members and 4 - 6 members purchased more food than households with 7 - 9 
Table 3. Impact of lockdown situation on food purchasing.

\begin{tabular}{lcccccc}
\hline & \multicolumn{5}{c}{ Household Size } \\
\cline { 2 - 6 } & Overall & $<3$ & $4-6$ & $7-9$ & $>10$ & p-value \\
\hline Purchase of food during COVID-19 lockdown $(\mathrm{n}=858)$ & & & & \\
\hline & $269(31.4)$ & $70(8.2)$ & $130(15.2)$ & $52(6.1)$ & $17(2.0)$ & 0.012 \\
Less than usual & $206(24.0)$ & $60(7.0)$ & $111(12.9)$ & $25(2.9)$ & $10(1.2)$ & $11(1.3)$ \\
$\quad$ Just as usual & $383(44.6)$ & $95(11.1)$ & $231(26.7)$ & $46(5.4)$ & \\
More foods than usual & &
\end{tabular}

Are you worried about how to continually feed yourself and/or your household if the COVID-19 lockdown is further extended? $(\mathrm{n}=853)$

\begin{tabular}{ccccccc}
\hline Yes & $538(63.1)$ & $127(14.9)$ & $288(33.8)$ & $93(10.9)$ & $30(3.5)$ & 0.001 \\
No & $315(36.9)$ & $96(11.3)$ & $182(21.3)$ & $29(3.4)$ & $8(0.9)$ & \\
\hline In the last 7 days, were there times when you did not have enough food or money to buy food? (n= 854) & \\
\hline Yes & $446(52.2)$ & $129(15.1)$ & $248(29.0)$ & $52(6.1)$ & $17(2.0)$ & 0.052 \\
No & $408(47.8)$ & $95(11.1)$ & $223(26.1)$ & $70(8.2)$ & $20(2.3)$ \\
\hline
\end{tabular}

members and $>10$ members (Table 3 ) which implies that households with higher size purchased less food than usual compared with smaller sized households $(\mathrm{p}=0.012)$. Similarly, households with $7-9$ members and $>10$ members reported shortage of food/money for food than household with $<3$ members and 4 - 6 members $(\mathrm{p}=0.05)$. These patterns suggest pressure on available financial resources in larger households and therefore corroborates the reasons earlier given for the category of "less than usual" spending behaviour. Further extension of movement restrictions was a source of worry for most of the respondents sampled in this survey based on household size $(p=0.001)$. Since most of the respondents had earlier mentioned being affected by stay at home orders, findings from this study confirm a fear of uncertainty and barriers to economic food access especially in larger sized households. These responses confirm a strain on access to food which in most cases was as a result of uncertainty during the period of lockdown.

\subsection{Experience of Food Insecurity}

Table 4 shows the affirmative responses to individual items on the Food Insecurity Experience Scale (FIES) questionnaire which probed food access in the previous 4 weeks. While $56.1 \%$ worried they would not have access to enough food to eat, $63.1 \%$ ate only a few kinds of foods and $53.3 \%$ had to skip a meal in the reference period. This indicated that the prevalent experience of more than half of the respondents clustered around worrying about running out of food, compromising on diet quality and reducing food quantities or skipping meals, as demonstrated by the higher affirmative responses to the first five FIES questions. The FIES tool measures food insecurity severity along a continuous scale of severity [8], it presents moderate food insecurity when individuals or households begin to eat low quality diets or are forced to also reduce the quantity of food 
Table 4. Food insecurity experience scale (FIES): Questions and categories.

\begin{tabular}{lc}
\hline \multicolumn{1}{c}{ Food Insecurity Experience Scale } & \multicolumn{1}{c}{$\begin{array}{c}\text { Frequency (\% of } \\
\text { total response) }\end{array}$} \\
\hline $\begin{array}{l}\text { Respondents worried about access to enough food to eat in the last } \\
30 \text { days }\end{array}$ & $485(56.1)$ \\
$\begin{array}{l}\text { Respondents unable to eat healthy and nutritious food in the last } \\
30 \text { days }\end{array}$ & $326(38.0)$ \\
$\begin{array}{l}\text { Respondents ate only a few kinds of foods in the last 30 days } \\
\text { Respondents had to skip a meal in the last 30 days }\end{array}$ & $543(63.2)$ \\
$\begin{array}{l}\text { Respondents ate less than he/she thought he/she should in the last } \\
\text { 30 days }\end{array}$ & $459(53.3)$ \\
$\begin{array}{l}\text { Respondents' household ran out of food in the last 30 days } \\
\text { Respondent was hungry but did not eat in the last 30 days }\end{array}$ & $223(26.2)$ \\
$\begin{array}{l}\text { Respondent had to go without eating for a whole day in the last } 30 \\
\text { days }\end{array}$ & $326(38.5)$ \\
\hline $\begin{array}{l}\text { Food Insecurity Experience Scale (FIES) Categories } \\
\text { Food Secure }\end{array}$ & $38(4.5)$ \\
$\begin{array}{l}\text { Moderately + Severely Food insecure } \\
\text { Severely Food insecure }\end{array}$ & $470(57.7)$ \\
\hline
\end{tabular}

they would normally eat. Those experiencing severe levels would have gone for entire days without eating, due to lack of money or other resources to have access to food; as shown by the responses to questions 6, 7 and 8. In this study, although very few of the respondents (4.5\%) went a whole day without eating anything because there was not enough food, more than a third gave a 'yes' response to the question "in the last 30 days (4 weeks), was there a time when you were hungry but did not eat?".

Overall, $57.7 \%$ of the respondents were food secure, $28.4 \%$, were experiencing either of moderate or severe forms of food insecurity and the severely food insecure households amounted to 113 (13.9\%) (Table 4). Going by definitions stated in the FIES methodology [7], the estimated number of respondents living in households where at least one adult was found to be food insecure is close to half. Numerical comparisons with previous national estimates were not done (due to statistical validation constraints). However, when a contextual comparison with reports in literature was done, the experiences reported in this study were not different from lockdown situations from different parts of the world [5] [9] [11] [12].

Further analysis of results in this study reveal that factors related to experiencing food insecurity were location, age, occupation, and income level (Table 5). Household size was not found to be significantly associated to experience of food insecurity. The associations between food insecurity and location can be 
Table 5. Food insecurity experience scale (FIES): Categories with socio-variables.

\begin{tabular}{|c|c|c|c|c|}
\hline & \multicolumn{4}{|c|}{ FIES Categories } \\
\hline & Food Secure & $\begin{array}{c}\text { Moderately } \\
\text { Food } \\
\text { Insecure }\end{array}$ & $\begin{array}{l}\text { Severely } \\
\text { Food } \\
\text { Insecure }\end{array}$ & p-value \\
\hline \multicolumn{5}{|l|}{ Categorization of neighborhood } \\
\hline Rural & $20(2.5)$ & $24(3.0)$ & $17(2.1)$ & 0.000 \\
\hline Semi-Urban & $136(16.9)$ & $63(7.8)$ & $39(4.8)$ & \\
\hline Urban & $310(38.5)$ & $140(17.4)$ & $57(7.1)$ & \\
\hline \multicolumn{5}{|l|}{ Household Size } \\
\hline$<3$ members & $125(15.6)$ & $66(8.2)$ & $27(3.4)$ & 0.256 \\
\hline $4-6$ members & $268(33.5)$ & $109(13.6)$ & $60(7.5)$ & \\
\hline 7 - 9 members & $56(7.0)$ & $36(4.5)$ & $19(2.4)$ & \\
\hline$>10$ members & $16(2.0)$ & $13(1.6)$ & $5(0.6)$ & \\
\hline \multicolumn{5}{|l|}{ Age of respondent } \\
\hline$<20$ years & $5(0.6)$ & $1(0.1)$ & $2(0.2)$ & 0.003 \\
\hline 21 - 30 years & $155(19.3)$ & $96(11.9)$ & $42(5.2)$ & \\
\hline $31-40$ years & $131(16.3)$ & $80(9.9)$ & $40(5.0)$ & \\
\hline $41-50$ years & $92(11.4)$ & $31(3.9)$ & $21(2.6)$ & \\
\hline $51-60$ years & $61(7.6)$ & $17(2.1)$ & $6(0.7)$ & \\
\hline$>60$ years & $21(2.6)$ & $3(0.4)$ & $1(0.1)$ & \\
\hline \multicolumn{5}{|l|}{ Occupation } \\
\hline Professional/technical/managerial & $142(31.6)$ & $51(22.9)$ & $25(23.6)$ & 0.014 \\
\hline Clerical & $56(12.5)$ & $17(7.6)$ & $11(10.4)$ & \\
\hline Sales and services & $63(14.0)$ & $36(16.1)$ & $22(20.8)$ & \\
\hline Skilled manual & $105(23.4)$ & $66(29.6)$ & $19(17.9)$ & \\
\hline Unskilled manual & $13(2.9)$ & $16(7.2)$ & $8(7.5)$ & \\
\hline Agriculture & $4(0.9)$ & $1(0.4)$ & $2(1.9)$ & \\
\hline Unemployed & $66(14.7)$ & $36(16.1)$ & $19(17.9)$ & \\
\hline \multicolumn{5}{|l|}{ Monthly Income (naira) } \\
\hline$<10,000$ naira & $40(5.1)$ & $35(4.5)$ & $24(3.1)$ & 0.000 \\
\hline 10,000 - 49,999 naira & $78(10.0)$ & $70(9.0)$ & $41(5.3)$ & \\
\hline 50,000 - 99,999 naira & $72(9.2)$ & $44(5.6)$ & $17(2.2)$ & \\
\hline 100,000 - 149,999 naira & $92(11.8)$ & $35(4.5)$ & $16(2.1)$ & \\
\hline 150,000 - 199,999 naira & $53(6.8)$ & $15(1.9)$ & $5(0.6)$ & \\
\hline$>200,000$ naira & $115(14.8)$ & $21(2.7)$ & $6(0.8)$ & \\
\hline
\end{tabular}

explained in various ways. Firstly, the disruptions to food supply chains which reduce access to food has been suggested to increase food insecurity [13]. This is 
particularly so with urban food systems where there are limited agricultural spaces. Amare et al., 2020 [14] presented evidence in Nigerian households to support the fact that areas with higher infection rates (and full lockdown restrictions) experienced high food insecurity. Age was significantly associated with experience of food insecurity ( $p=0.003$ ), which was most experienced by respondents aged 21 - 30 years. A similar observation has been reported in literature [15] [16] but it is unclear if the experience of Nigerian respondents is caused by the inability to earn during lockdown or the inability to be thrifty with available resources.

As regards occupation, food insecurity $(\mathrm{p}=0.014)$ was high in households where the respondent's source of income was artisanship or personal business under the skilled manual category. This implies that respondents who usually relied on day-to-day business activities were most affected since about $91 \%$ of respondents claimed to be staying at home and unable to go to work. This is further explained by the relationship observed between monthly income and experience of food insecurity $(p=0.000)$. The association of food insecurity with income levels seems straightforward to explain since higher income levels will definitely suggest some means of adjustability to the lockdown situation. Also, since most of the respondents depended on a monthly salary as their main income source, it is logical to assume that disruptions to flow of income was a major factor in determining economic access to food and by extension the experience of food insecurity (or otherwise). This assertion is mirrored in literature presented in the earliest and recent waves of COVID-19 [16] [17]. An old and recent assessment carried out on expenditure patterns of American households (during and after lockdown restrictions) asserts likewise [10] [12]. A study of Ethiopian households shows that higher income earners who relied on savings were able to circumnavigate any shocks on their household food expenditure [9].

\section{Conclusion}

This study presents findings on economic and behavioral patterns related to food access during COVID-19 lockdown in Nigeria. Evidence is presented showing substantial alterations to usual purchasing patterns of food coupled with mild experience of food insecurity. Although the responses captured respondents' own perspectives regarding the adequacy of their food consumption, the findings indicate that overall, there was disruption in physical or economic access to food which was common to all respondents. On the average, individuals in smaller households reported buying more food when compared to households with larger sizes. Evidently, the latter experienced more strain of food expenditure and were more likely to complain of lack of economic access to food. However, many respondents expressed worry and uncertainty of coping with access to affordable food if the existing restrictions persisted. This study is not without some limitations; firstly, respondents were restricted to smartphone users which limited participation to a small audience. Secondly, most of the respondents 
were from the urban centers with less from rural areas. Overall, the experience of severe food insecurity is not generally a serious problem; however, most respondents reported worry of physical and economic instability regarding food access and had fears of an uncertain future if lockdown restrictions persisted. The possible pathways through which these observations can impact optimum nutritional status are in two parts. Firstly, these alterations suggest a possible decline in diet quality which inevitably results in undernutrition. Another silent but salient challenge posed by this food access alterations is the burden of consuming excess above nutrient adequacy. Households with financial ability to stock up more food may find themselves having more meals and expending less energy since they are on lockdown. Either of these two pathways can give rise to serious health consequences on the short and long terms. A pre- and post-impact of these food access alterations on national nutrition indicators especially in vulnerable age groups is hereby recommended.

\section{Acknowledgements}

The authors appreciate all respondents who filled the questionnaire and assisted in sharing with their contacts.

\section{Conflicts of Interest}

The authors declare no conflicts of interest regarding the publication of this paper.

\section{References}

[1] FAO, IFAD, UNICEF, WFP and WHO (2020) The State of Food Security and Nutrition in the World 2020. Transforming Food Systems for Affordable Healthy Diets. FAO, Rome. https://doi.org/10.4060/ca9692en

[2] FAO, IFAD, UNICEF, WFP and WHO (2021) The State of Food Security and Nutrition in the World 2021. Transforming Food Systems for Food Security, Improved Nutrition and Affordable Healthy Diets for All. FAO, Rome. https://doi.org/10.4060/cb4474en

[3] Obayelu, O.A. and Akpan, E.I. (2021) Food Insecurity Transitions among Rural Households in Nigeria. Studies of Applied Economics, 39. https://doi.org/10.25115/eea.v39i2.3505

[4] Sanusi, R.A., Samuel, F.O., Ariyo, O. and Eyinla, T.E. (2019) Achieving Food Security in Nigeria by 2050. African Journal of Medicine and Medical Sciences, 4, 23-27.

[5] Niles, M.T., Bertmann, F., Belarmino, E.H., Wentworth, T., Biehl, E. and Neff, R.A. (2020) The Early Food Insecurity Impacts of COVID-19. medRxiv. https://doi.org/10.1101/2020.05.09.20096412

[6] Silverio, R., Gonçalves, D.C., Andrade, M.F. and Seelaender, M. (2020) Coronavirus Disease 2019 (COVID-19) and Nutritional Status: The Missing Link? Advances in Nutrition, 12, 682-692. https://doi.org/10.1093/advances/nmaa125

[7] FAO (2016) Methods for Estimating Comparable Rates of Food Insecurity Experienced by Adults throughout the World. FAO, Rome.

http://www.fao.org/3/a-i4830e.pdf 
[8] FAO (2018) Voices of the Hungry. Food and Agriculture Organization of the United Nations, Rome. www.fao.org/in-action/voices-of-the-hungry

[9] Hirvonen, K., Abate, G.T. and de Brauw, A. (2020) Survey Suggests Rising Risk of Food and Nutrition Insecurity in Addis Ababa, Ethiopia, as COVID-19 Restrictions Continue. In: Swinnen, J. and McDermott, J., Eds., COVID-19 and Global Food Security, Part Two: Diets and Nutrition, Chapter 10, International Food Policy Research Institute (IFPRI), Washington DC, 46-49.

https://doi.org/10.2499/p15738coll2.133762 10

[10] Baker, S.R., Farrokhnia, R.A., Meyer, S., Pagel, M. and Yannelis, C. (2020) How Does Household Spending Respond to an Epidemic? Consumption during the 2020 Covid-19 Pandemic. The Review of Asset Pricing Studies, 10, 834-862. https://doi.org/10.1093/rapstu/raaa009

[11] Loopstra, R. (2020) Vulnerability to Food Insecurity since the COVID-19 Lockdown: Preliminary Report. ENUF.

https://foodfoundation.org.uk/sites/default/files/2021-10/Report COVID19FoodIns ecurity-final.pdf

[12] Clay, L.A. and Rogus, S. (2021) Food Access Worries, Food Assistance Use, Purchasing Behavior, and Food Insecurity among New Yorkers during COVID-19. Frontiers in Nutrition, 8, Article ID: 647365. https://doi.org/10.3389/fnut.2021.647365

[13] Swinnen, J. and McDermott, J. (2020) COVID-19 and Global Food Security. International Food Policy Research Institute (IFPRI), Washington DC. https://doi.org/10.2499/p15738coll2.133762

[14] Amare, M., Abay, K.A., Tiberti, L. and Chamberlin, J. (2020) Impacts of COVID-19 on Food Security: Panel Data Evidence from Nigeria. IFPRI Discussion Paper 1956. International Food Policy Research Institute (IFPRI), Washington DC. https://doi.org/10.2499/p15738coll2.133866

[15] Oldewage-Theron, W., Abu, B.A., Nguyen, B. and Saha, S. (2018) Food Insecurity and Food Access among Seniors in Lubbock, Texas. Journal of Hunger \& Environmental Nutrition, 15, 1-15. https://doi.org/10.1080/19320248.2018.1512920

[16] Furey, S., McLaughlin, C., Beacom, E., Quinn, U. and Surgenor, D. (2019) What Predicts Food Insecurity? An Online Survey. The Lancet, 394, S41. https://doi.org/10.1016/S0140-6736(19)32838-7

[17] Méndez-Pérez, M., Monroy-Torres, R., Delgado-Sandoval, S. and Medina-Jiménez, K. (2021) Food and Nutritional Insecurity before and during the COVID-19 Pandemic in Households of Women Belonging to a Social Program. Food and Nutrition Sciences, 12, 742-758. https://doi.org/10.4236/fns.2021.127056 